\title{
Электрооптическая амплитудная модуляция излучения на базе резонаторов Фабри-Перо
}

\author{
В.Б. Залесский, А.И. Конойко, В.М. Кравченко, А.С. Мицкевич \\ ГНПО «Оптика, оптоэлектроника и лазерная техника», Беларусь, г.Минск, 220072, nр-кт \\ Независимости, 68, тел.: +375173553425;e-mail: kon54@yandex.by
}

DOI 10.34077/RCSP2019-43

В этом докладе рассматриваются вопросы, уменьшения управляющего напряжения элетрооптических амплитудных модуляторов на базе резонаторов Фабри-Перо с поперечным приложением управляющего поля на примере ниобата лития $\mathrm{LiNbO}_{3}$. Предлагается метод амплитудной электрооптической амплитудной модуляции излучения последовательностью резонаторов Фабри-Перо. Этот метод позволяет существенно уменьшить значение управляющего напряжения электрооптического амплитудного модулятора работающего в режиме пропускания светового пучка при сохранении его высокой эффективности. Уменьшение управляющего напряжения осуществляется за счет, как увеличения количества установленных последовательно резонаторов Фабри-Перо, так и фазового сдвига относительно экстремума функции коэффициента пропускания.

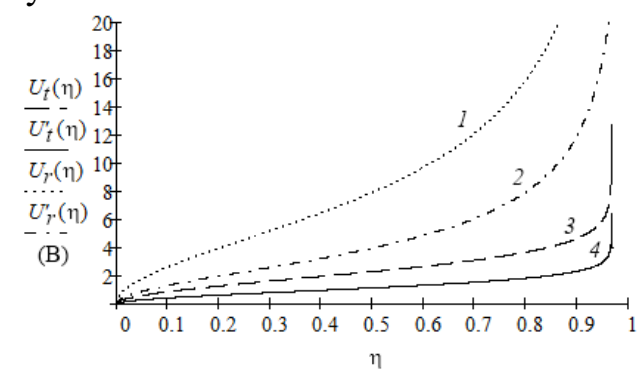

a

исунок 1 - Зависимости управляющего напряжения модулятора на базе резонаторов ФабриПеро от а - требуемой эффективности модуляции излучения; б - количества установленных последовательно резонаторов

На рисунке 1a показаны графики расчетных зависимостей управляющих напряжений, соответственно $U_{r}$ и $U_{r}$ (кривые 1,2 ), от требуемой эффективности модуляции $\eta[1]$ при использовании одного резонатора, работающего на отражение. При использовании 1 резонатора, работающего на пропускание, зависимости управляющих напряжений от требуемой эффективности модуляции будут соответствовать кривым 1 и 2 . Графики 3,4 соответствуют зависимостям управляющих напряжений $U_{t}$ и $U_{t}$ от требуемой эффективности модуляции $\eta$ при использовании девяти резонаторов, работающих на пропускание. Кривые 1,3 соответствуют режиму модуляции излучения, когда начальная рабочая точка резонаторов соответствует минимальному отражению, а кривые 2,4 когда его начальная рабочая точка сдвинута по фазе относительно экстремума функции коэффициента отражения, то есть его минимума, на величину равную $(2 \pi / \lambda) \cdot\left(\delta n l_{0}\right)$, где $\delta n-$ изменение показателя преломления $(\delta n)$ в случае поперечного электрооптического эффекта при использовании в качестве электрооптической среды ниобата лития $\mathrm{LiNbO}_{3}$, которое можно найти из выражения [2]. На рисунке 16 показаны графики расчетной зависимости зависимости величины управляющего напряжения $U_{t}$ и $U_{t}{ }^{\prime}$ модулятора излучения с эффективностью $\eta_{t}=0,8$, работающего на пропускание, от количества установленных последовательно электрооптических резонаторов Фабри-Перо.

Приведенные зависимости показывают возможность снижения управляющего напряжения для модулятора Фабри-Перо, выполненного на базе электрооптического кристалла ниобата лития $\mathrm{LiNbO}_{3}$, до значения порядка $4 \mathrm{~B}$, в случае, когда его начальная рабочая точка соответствует максимальному пропусканию и до значения порядка 2 В, в случае, когда его начальная рабочая точка сдвинута по фазе относительно экстремума функции коэффициента пропускания на величину равную $(2 \pi / \lambda) \cdot\left(\delta n l_{0} / 2\right)$. При этом длительность оптических сигналов уменьшается на $30 \%$.

\section{Литература}

[1] Е.П. Мустель, В.Н. Парыгин. Методы модуляции и сканирования света. М., Наука, 1970. 296 с. 